\title{
Desempenho agronômico de plantas de cobertura usadas na proteção do solo no período de pousio
}

\author{
Wellington Pereira de Carvalho(1), Gabriel José de Carvalho(2), Dyrson de Oliveira Abbade Neto(2) \\ e Luíz Gustavo Vieira Teixeira ${ }^{(2)}$
}

\begin{abstract}
(1)Embrapa Cerrados, BR 020, Km 18, Caixa Postal 08223, CEP 73310-970 Planaltina, DF. E-mail: wellington.carvalho@embrapa.br (2)Universidade Federal de Lavras, Caixa Postal 3037, CEP 37200-000 Lavras, MG. E-mail: gab@ufla.br, dyrson.po@gmail.com, luguteixeira@yahoo.com.br
\end{abstract}

\begin{abstract}
Resumo - O objetivo deste trabalho foi identificar espécies com alta produção de fitomassa, para proteção do solo no período de pousio. O experimento foi realizado com três espécies da família Leguminosae e três da família Poaceae, de 2009 a 2010, na área experimental do campus da Universidade Federal de Lavras, Minas Gerais. As espécies avaliadas foram: crotalária anagiroide (Crotalaria anagyroides), feijão-de-porco (Canavalia ensiformis), guandu-anão (Cajanus cajan), aveia-preta (Avena strigosa), sorgo (Sorghum bicolor) e milheto (Pennisetum glaucum), semeadas em cultivo solteiro e consorciado. O feijão-de-porco e o sorgo apresentaram as maiores taxas de cobertura do solo em cultivo solteiro, enquanto o milheto apresentou a menor. O sorgo, em cultivo solteiro e consorciado com feijão-de-porco e guandu-anão, apresenta a maior produção de matéria verde e matéria seca, enquanto o guandu-anão apresenta a menor produção de matéria verde, e a crotalária anagiroide, a menor produção de matéria seca. Por ocasião da implantação da cultura comercial, o tratamento que proporcionou a maior quantidade de palha sobre o solo foi o consórcio entre feijão-de-porco e sorgo.
\end{abstract}

Termos para indexação: Avena strigosa, Cajanus cajan, Pennisetum glaucum, Sorghum bicolor, cultivo consorciado, taxa de cobertura.

\section{Agronomic performance of cover crops used as ground cover mulching in the fallow period}

\begin{abstract}
The objective of this work was to identify species with high production of phytomass for ground cover in the fallow period. The experiment was carried out from 2009 to 2010, with three species of the family Leguminosae and three of the family Poaceae, in the experimental area of the campus of the Universidade Federal de Lavras, Minas Gerais, Brazil. The evaluated species were: caracas rattlebox (Crotalaria anagyroides), jack bean (Canavalia ensiformis), pigeon pea (Cajanus cajan), black oat (Avena strigosa), sorghum (Sorghum bicolor) and pearl millet (Pennisetum glaucum), sown with and without intercropping. Jack bean and sorghum showed the highest rate of soil covering in single cropping, whereas pearl millet the lowest. Sorghum in single cropping and intercropped with jack bean and pigeon pea shows the largest production of green matter and dry matter, whereas pigeon pea presents the lowest production of green matter, and caracas rattlebox the lowest production of dry matter. At the implantation of the commercial culture, the largest amount of straw above the soil was provided by the intercropping between jack bean and sorghum.
\end{abstract}

Index terms: Avena strigosa, Cajanus cajan, Pennisetum glaucum, Sorghum bicolor, intercropping, rate of soil covering.

\section{Introdução}

A prática de proteger o solo com plantas de cobertura ou adubos verdes é vantajosa não somente durante o verão, mas também na entressafra, especialmente na região do Cerrado, onde as áreas agricultáveis ficam sujeitas à radiação solar, à erosão eólica e à infestação por plantas espontâneas no período de pousio (Balbinot Júnior et al., 2008). Neste sentido, a sucessão de culturas com a safrinha, além de possibilitar a diversificação das atividades na propriedade, ocupa parte do período de pousio e é uma prática recomendável em sistemas agrícolas sustentáveis (Balbinot Júnior et al., 2009).

O uso de culturas de cobertura no período de safrinha pode melhorar a qualidade do solo (Giacomini et al., 2003). A produção de matéria seca das espécies utilizadas para cobertura do solo depende das condições climáticas, edáficas, fitossanitárias, das práticas de 
manejo e, em grande parte, também da agressividade do sistema radicular, uma vez que sua profundidade está relacionada à maior produção de biomassa (Carvalho \& Amabile, 2006).

A vantagem da utilização de plantas de cobertura da família das leguminosas está no seu potencial de produção de biomassa e na sua capacidade de fornecer nitrogênio à cultura sucessora (Matheis et al., 2006). Entretanto, essas plantas apresentam baixa relação $\mathrm{C} / \mathrm{N}$ e podem apresentar elevada taxa de decomposição de seus resíduos (Teixeira et al, 2009). Já as poáceas destacam-se pela alta produção de biomassa e de resíduos com relação $\mathrm{C} / \mathrm{N}$ elevada, o que pode contribuir para redução na taxa de decomposição e para liberação mais lenta de nutrientes no solo (Silva et al., 2012). Além disso, o uso de poáceas como plantas de cobertura é importante para a absorção de nutrientes, especialmente do potássio, de camadas subsuperficiais e disponibilização na superfície do solo (Boer et al., 2007).

O cultivo consorciado dessas espécies pode proporcionar benefícios aos sistemas de produção. Isso porque essas plantas apresentam características intrínsecas que resultam na exploração de camadas distintas de solo, no favorecimento de grupos da biota do solo, na ciclagem diferenciada de nutrientes (Cherr et al., 2006), na estruturação física do solo e na produção de matéria seca com relação $\mathrm{C} / \mathrm{N}$ intermediária, que permitiria menor taxa de decomposição de resíduos culturais. Neste contexto, avaliar o desempenho de espécies consorciadas é de alta relevância.

O objetivo deste trabalho foi identificar, espécies com alta produção de fitomassa, para proteção do solo no período de pousio.

\section{Material e Métodos}

O experimento foi conduzido no campo experimental do Departamento de Agricultura da Universidade Federal de Lavras, Minas Gerais $\left(21^{\circ} 14^{\prime} \mathrm{S}\right.$ e $45^{\circ} 00^{\prime} \mathrm{W}$, a 919 m de altitude), durante três anos (2008, 2009 e 2010), no período da safrinha, ou seja, durante a primeira quinzena de março. De acordo com a classificação de Köppen, o clima da região é de transição entre Cwb e Cwa, com duas estações bem definidas, uma fria e seca, de abril a setembro, e uma quente e úmida, de outubro a março. Os dados de precipitação, umidade relativa e temperatura, no período experimental, estão descritos na Figura 1.

A análise do solo da área experimental, classificado como Latossolo Vermelho distroférrico (Santos et al., 2006), indicou, na profundidade $0-20 \mathrm{~m}$, os seguintes resultados: $\mathrm{pH}\left(\mathrm{H}_{2} \mathrm{O}\right) 6,0 ; 0,1 \mathrm{cmol} \mathrm{dm}^{-3}$ de $\mathrm{Al}$; 2,2 $\mathrm{mg} \mathrm{dm}^{-3}$ de P; 61,3 $\mathrm{mg} \mathrm{dm}^{-3}$ de $\mathrm{K} ; 1,9 \mathrm{cmol} \mathrm{dm}^{-3}$ de $\mathrm{Ca}$; $0,8 \mathrm{cmol} \mathrm{dm}^{-3}$ de $\mathrm{Mg} ; 2,9 \mathrm{cmol} \mathrm{dm}^{-3} \mathrm{de} \mathrm{H}+\mathrm{Al}$; 2 dag $\mathrm{kg}^{-1}$ de MO; $1,7 \mathrm{mg} \mathrm{dm}^{-3}$ de Zn; 365,8 $\mathrm{mg} \mathrm{dm}^{-3}$ de Fe; $45 \mathrm{mg} \mathrm{dm}^{-3}$ de Mn; $3 \mathrm{mg} \mathrm{dm}^{-3}$ de Cu; 0,2 $\mathrm{mg} \mathrm{dm}^{-3}$ de $\mathrm{B} ; 9,1 \mathrm{mg} \mathrm{dm}^{-3}$ de $\mathrm{S} ; 490 \mathrm{~g} \mathrm{~kg}^{-1}$ de areia; $153 \mathrm{~g} \mathrm{~kg}^{-1}$ de silte; e $357 \mathrm{~g} \mathrm{~kg}^{-1}$ de argila.

A área experimental esteve sob pastagem de Urochloa brizantha (Syn. Brachiaria brizantha) nos três anos anteriores à instalação do experimento. Em fevereiro de 2008, realizou-se calagem, de acordo com a análise de solo, e posterior aração com grade aradora, seguida de gradagem niveladora para destorroamento. Na segunda semana de março, procedeu-se a outra gradagem niveladora, com abertura dos sulcos e semeadura manual das espécies de plantas de cobertura. Como, experimentalmente, não houve controle de plantas infestantes após a semeadura, houve comprometimento da maioria das parcelas, e, portanto, não foram coletados dados naquele ano. Em 2009, foi realizada capina manual da área, na segunda semana de março, com abertura manual dos sulcos e semeadura manual das espécies de plantas de cobertura, em cultivo mínimo (sem revolvimento do solo). Aos 30 dias após a emergência (DAE), efetuouse nova capina manual.

As plantas de cobertura utilizadas foram as leguminosas crotalária anagiroide (Crotalaria anagyroides Kunth), feijão-de-porco [Canavalia ensiformis (L.) DC] e guandu-anão [Cajanus cajan (L). Millsp.]; e as poáceas aveia-preta (Avena strigosa Schreb), sorgo [Sorghum bicolor (L.) Moench, cultivar BRS 506] e milheto [Pennisetum glaucum (L.) R.Br., variedade BRS 1501].

Utilizou-se o delineamento experimental de blocos ao acaso, com quatro repetições e 16 tratamentos: crotalária anagiroide; feijão-de-porco; guandu-anão; aveia-preta;sorgo; milheto; crotalária anagiroide + aveia-preta; crotalária anagiroide + sorgo; crotalária anagiroide + milheto; feijão-de-porco + aveia-preta; feijão-de-porco + sorgo; feijão-de-porco + milheto; guandu-anão + aveia-preta; guandu-anão + sorgo; guandu-anão + milheto e testemunha com vegetação 
espontânea. As parcelas apresentaram dimensões de $4 \mathrm{~m}$ de largura e $4 \mathrm{~m}$ de comprimento, com bordadura de $0,5 \mathrm{~m}$, nas laterais e nas extremidades das linhas, e área útil de $9 \mathrm{~m}^{2}$.

As espécies de plantas de cobertura foram semeadas no espaçamento de $0,5 \mathrm{~m}$ entre linhas, quando em cultivo solteiro (feijão-de-porco e três poáceas), e no espaçamento de $0,25 \mathrm{~m}$ entre linhas, para crotalária anagiroide e guandu-anão, em cultivo solteiro e consorciado. Não foram feitas aplicações de fertilizantes na semeadura e em cobertura. Aos $20 \mathrm{DAE}$, foi feito o desbaste, tendo-se ajustado a população de plantas para dez plantas por metro, para feijão-de-porco, milheto e sorgo solteiros e consorciados; 25 e 20 plantas por metro, para crotalária e guandu-anão solteiros e consorciados, respectivamente; dez plantas por metro, para milheto solteiro e consorciado; dez plantas por metro, para sorgo solteiro e consorciado; e 40 plantas por metro, para aveia-preta solteira e consorciada (Sodré Filho et al., 2004). As leguminosas foram inoculadas com inoculante específico (coquetel das estirpes CPAC-C2, CPAC-B10 e CPAC-F2).

O período decorrido entre o plantio e o corte das plantas de cobertura, quando $50 \%$ das plantas estavam no período de floração, foi de 75 dias, para milheto e aveia-preta; 80 dias, para guandu-anão e vegetação espontânea; 91 dias, para sorgo e feijão-de-porco; e 121 dias, para crotalária anagiroide. Para os tratamentos em consórcio, o corte foi realizado quando a espécie mais precoce atingiu 50\% de floração. Em 2010, repetiu-se o mesmo procedimento de 2009 , e o período decorrido entre a semeadura e o corte das plantas de cobertura, quando $50 \%$ das plantas estavam no período de floração, foi de 76 dias, para milheto e aveia-preta; 82 dias, para guandu-anão e vegetação espontânea; 90 dias, para sorgo e feijão-de-porco; e 118 dias, para crotalária anagiroide.

Em 2009 e 2010, foram avaliadas as seguintes variáveis: taxa de cobertura do solo proporcionada pelas plantas de cobertura; massa de matéria verde das

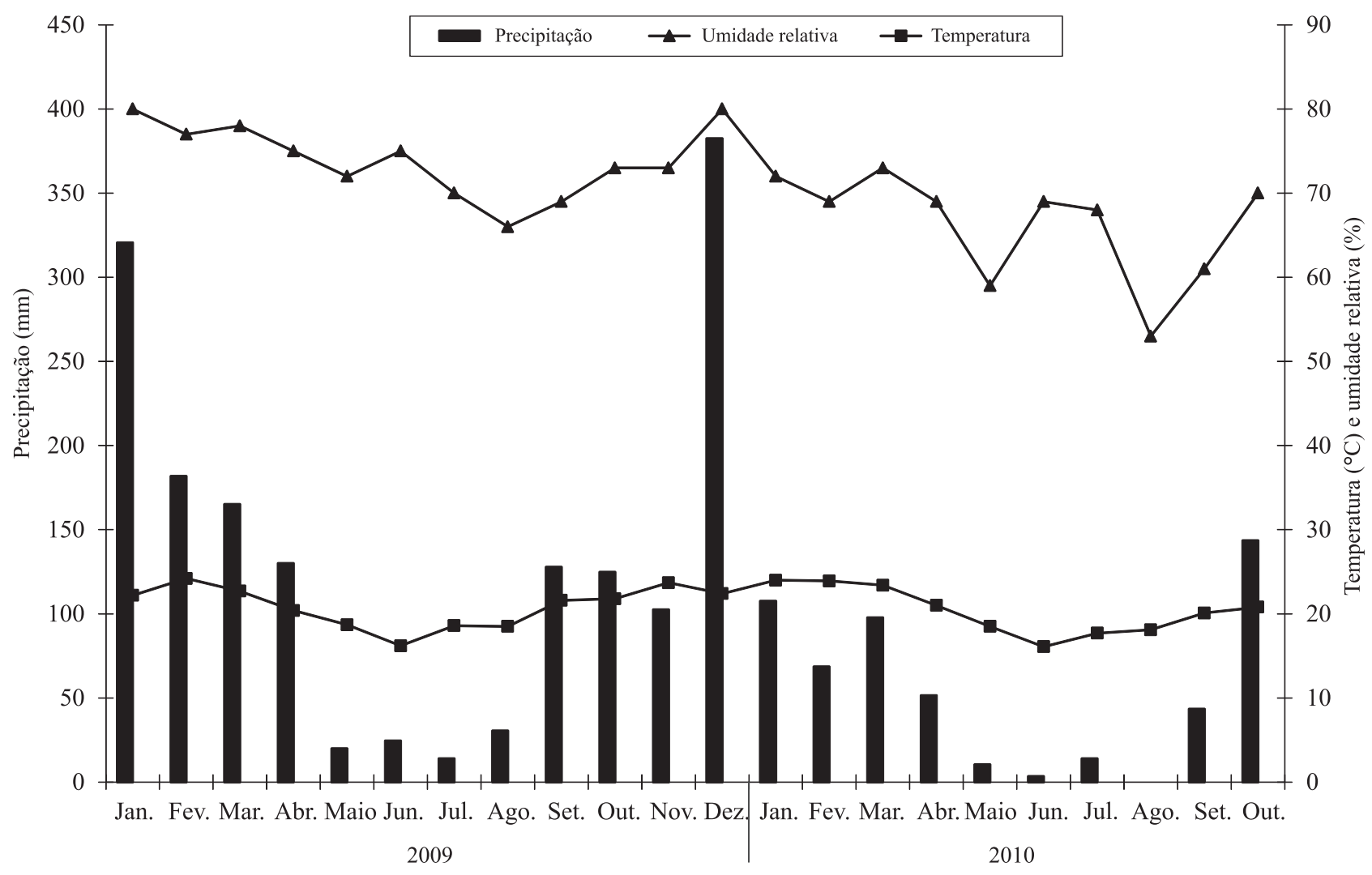

Figura 1. Temperatura média mensal $\left({ }^{\circ} \mathrm{C}\right)$, precipitação pluvial $(\mathrm{mm})$ e umidade relativa do ar $(\%)$ no local do experimento, em 2009 e 2010. 
plantas de cobertura após o corte; massa de matéria seca após o corte; percentagem de cobertura do solo por palhadas das plantas de cobertura, em setembro (antes do início do período chuvoso) e em outubro (após o início do período chuvoso); e massa de matéria seca das plantas de cobertura antes da semeadura da cultura sucessora.

A taxa de cobertura aos $15,30,45,60$ e 75 DAE, pelas plantas de cobertura, foi avaliada com uso de quadrado de madeira de $0,5 \mathrm{~m}$ de lado, com rede de barbantes espaçados a cada $0,05 \mathrm{~m}$, em que a presença ou não da cobertura vegetal dentro dos espaços entre os barbantes foi empregada para determinar a cobertura do solo proporcionada (Sodré Filho et al., 2004).

Quando cada tratamento atingiu 50\% de floração, retirou-se uma subamostra de $1 \mathrm{~m}^{2}$ de dentro da área útil das parcelas, tendo-se coletado separadamente, nos tratamentos consorciados, toda a parte aérea de poáceas e leguminosas, que foram acondicionadas em sacos de papel. As amostras foram levadas para secagem em estufa com circulação forçada de ar, a $60^{\circ} \mathrm{C}$, até atingirem massa de matéria seca constante. A partir da massa de matéria seca das poáceas e das leguminosas, e da massa de matéria seca total após o corte, foi calculada a percentagem de poáceas e leguminosas desses tratamentos. Em seguida, as plantas foram cortadas com roçadeira costal motorizada, e todo o material da área útil foi reunido, ensacado - para determinar a massa de matéria verde após o corte - e novamente espalhado no local de origem. Esses dados foram utilizados para calcular a relação massa de matéria verde /massa de matéria seca (RVS).

No primeiro dia de setembro, antes do início do período chuvoso, avaliou-se a percentagem de cobertura das palhadas das plantas de cobertura, tendo-se lançado o quadrado de madeira de $0,5 \mathrm{~m}$, com a rede de barbantes, quatro vezes por parcela. $\mathrm{O}$ período médio decorrido entre o corte das plantas de cobertura e a avaliação foi de 109 dias, para milheto e aveia-preta; 90 dias, para guandu-anão e vegetação espontânea; 79 dias, para sorgo e feijão-de-porco; e 50 dias, para crotalária anagiroide. O mesmo procedimento foi repetido 60 dias depois, em 31 de outubro, com precipitação pluvial acumulada durante o período de $252,6 \mathrm{~mm}$, em 2009 , e de $186,9 \mathrm{~mm}$ em 2010. Na segunda semana de novembro, coletou-se toda a palha remanescente na área útil das parcelas, que foi pesada e espalhada novamente no local de origem, para se obter a massa de palhada das plantas de cobertura antes da semeadura da cultura sucessora.

Os dados foram submetidos à análise de variância por meio do programa computacional Sisvar, e, nos casos de significância pelo teste $\mathrm{F}$, as médias foram agrupadas pelo teste de Scott-Knott, a 5\% de probabilidade. Também foi realizada análise de correlação entre as variáveis avaliadas.

\section{Resultados e Discussão}

Os consórcios feijão-de-porco + aveia-preta e feijão-de-porco + sorgo foram os tratamentos que proporcionaram maior taxa de cobertura do solo aos 15 DAE (Tabela 1). O milheto, em cultivo solteiro, proporcionou a menor taxa de cobertura em todas as avaliações, com $38,5 \%$ da área coberta pelo consórcio feijão-de-porco + sorgo, aos 75 dias. Esse resultado é indicativo de que o espaçamento utilizado para o milheto, de $0,5 \mathrm{~m}$, não foi o ideal para um adequado revestimento do solo pela planta, em condição de déficit hídrico. Possivelmente, o espaçamento de $0,25 \mathrm{~m}$ utilizado para crotalária anagiroide e guandu-anão teria proporcionado melhor cobertura. Mechede et al. (2007), com uso do espaçamento de $0,5 \mathrm{~m}$ no período da seca, mas com irrigação, obtiveram taxa de cobertura de $91,25 \%$ para milheto em cultivo solteiro. $\mathrm{Na}$ avaliação realizada aos $75 \mathrm{DAE}$, os consórcios feijão-de-porco + aveia-preta, feijão-de-porco + milheto, feijão-de-porco + sorgo, guandu-anão + sorgo e crotalária anagiroide + sorgo proporcionaram maior taxa de cobertura do solo.

$\mathrm{Na}$ comparação entre as três leguminosas em cultivo solteiro, o feijão-de-porco apresentou crescimento inicial rápido e maior cobertura do solo pela parte aérea, em todas as avaliações (Figura 2). Esse comportamento também foi verificado, em campo, por Carvalho \& Amabile (2006), que atribuem essa característica ao crescimento acelerado e às amplas folhas cotiledonares da espécie, que favorecem a rápida cobertura do solo. A crotalária anagiroide e o guandu-anão apresentaram cobertura do solo inicial superior à da vegetação espontânea (testemunha), mas foram superadas por esta a partir de 21 dias do plantio. Favero et al. (2001) avaliaram a taxa de cobertura de cinco leguminosas e constataram que o feijão-de-porco proporcionou cobertura de 51,83 e $81 \%$ aos 28,54 e 86 DAE, respectivamente. Os autores relataram sinais de início 
de senescência por ocasião da última avaliação, com diminuição na biomassa, ressecamento e queda de folhas mais baixas, e consequente redução na cobertura do solo, na terceira época de avaliação. No presente trabalho, o feijão-de-porco teve crescimento contínuo da emergência até a floração, aos 75 DAE, quando foi cortado sem apresentar sinais de senescência. A partir da derivada da equação de regressão obtida, constatou-se que a época em que o feijão-de-porco atingiria a maior taxa de cobertura do solo seria aos 84 DAE. O crescimento do guandu-anão foi inferior ao do feijão-de-porco até a época do corte. Favero et al. (2001) também observaram taxa de cobertura inferior pelo guandu-anão em comparação ao feijão-de-porco até a avaliação aos 54 DAE. No entanto, após esse período, os autores observaram maior crescimento da parte aérea do guandu-anão, que chegou a proporcionar $44 \%$ de cobertura aos 86 DAE, tendo superado a do feijão-de-porco.

As curvas de regressão entre a taxa de cobertura e a época de amostragem ajustaram-se ao modelo quadrático para todos os tratamentos avaliados (Figura 2). A curva representada pelo sorgo apresentou comportamento semelhante à da testemunha, apesar dos diferentes tipos de hábito de crescimento, com o sorgo mostrando maior crescimento inicial. Para sorgo semeado em setembro, na mesma área e sob as mesmas condições de adubação e espaçamento, Barros
(2009) obteve taxa de cobertura do solo de 11, 54 e $66 \%$ aos 17, 27 e 39 dias após a semeadura (DAS), respectivamente. Esse resultado mostra crescimento inicial mais acelerado até 27 DAS, em razão da época mais favorável à semeadura, e, após esse período (39 DAS), a taxa de cobertura assemelha-se à obtida aos 45 dias no presente trabalho, que foi de $66 \%$. Pelo estudo de derivada, a época em que o sorgo atingiria a maior taxa de cobertura do solo seria aos 91 DAE. As taxas de cobertura da aveia-preta e do milheto foram inferiores às do sorgo e da testemunha.

As curvas de regressão para crotalária anagiroide consorciada com as três poáceas mostraram que os consórcios com aveia-preta e sorgo apresentaram taxas de cobertura semelhantes aos $15 \mathrm{DAE}$; após essa primeira leitura, houve maior aumento da cobertura do solo no consórcio com sorgo (Figura 3). O consórcio com milheto teve crescimento inicial mais acelerado que a testemunha, mas após os $45 \mathrm{DAE}$, foi superado e apresentou a menor taxa de cobertura na época do corte.

Para o feijão-de-porco, os consórcios com aveia-preta e sorgo apresentaram incremento da cobertura do solo semelhante ao longo das amostragens, apesar da diferença de altura de planta entre as duas poáceas (Figura 3). A aveia-preta, em decorrência da má adaptação ao período da safrinha na região, apresentou altura média, na época do corte, de $0,45 \mathrm{~m}$,

Tabela 1. Taxa de cobertura do solo $(\%)^{(1)}$ proporcionada pela parte aérea de plantas de cobertura aos $15,30,45,60$ e 75 dias após a emergência (DAE) $)^{(2)}$.

\begin{tabular}{|c|c|c|c|c|c|}
\hline Espécie & $15 \mathrm{DAE}$ & $30 \mathrm{DAE}$ & $45 \mathrm{DAE}$ & $60 \mathrm{DAE}$ & $75 \mathrm{DAE}$ \\
\hline Feijão-de-porco + aveia-preta & $42,75 \mathrm{a}$ & $64,75 \mathrm{a}$ & $90,50 \mathrm{a}$ & $99,00 \mathrm{a}$ & $99,50 \mathrm{a}$ \\
\hline Feijão-de-porco + sorgo & $39,75 \mathrm{a}$ & $64,00 \mathrm{a}$ & $95,25 \mathrm{a}$ & $100,00 \mathrm{a}$ & $100,00 \mathrm{a}$ \\
\hline Feijão-de-porco + milheto & $31,00 \mathrm{~b}$ & $56,00 \mathrm{a}$ & $88,50 \mathrm{a}$ & $97,00 \mathrm{a}$ & $99,50 \mathrm{a}$ \\
\hline Feijão-de-porco & $24,75 b$ & $43,25 b$ & $70,50 \mathrm{~b}$ & $83,75 b$ & $87,50 \mathrm{~b}$ \\
\hline Guandu-anão + sorgo & $17,75 \mathrm{c}$ & $48,50 \mathrm{~b}$ & $91,00 \mathrm{a}$ & $97,00 \mathrm{a}$ & $98,25 \mathrm{a}$ \\
\hline Crotalária anagiroide + sorgo & $17,75 \mathrm{c}$ & $40,25 b$ & $86,75 \mathrm{a}$ & $96,00 \mathrm{a}$ & $96,50 \mathrm{a}$ \\
\hline Crotalária anagiroide + aveia-preta & $16,25 \mathrm{c}$ & $29,25 \mathrm{c}$ & $64,00 \mathrm{c}$ & $77,75 b$ & $82,25 b$ \\
\hline Guandu-anão + aveia-preta & $11,20 \mathrm{c}$ & $16,75 \mathrm{~d}$ & $62,00 \mathrm{c}$ & $71,50 \mathrm{c}$ & $77,25 b$ \\
\hline Crotalária anagiroide + milheto & $9,75 \mathrm{c}$ & $23,50 \mathrm{c}$ & $52,75 \mathrm{~d}$ & $68,75 \mathrm{c}$ & $77,75 b$ \\
\hline Crotalária anagiroide & $9,50 \mathrm{c}$ & $14,75 \mathrm{~d}$ & $27,75 f$ & $52,75 d$ & $58,50 \mathrm{c}$ \\
\hline Sorgo & $9,25 \mathrm{c}$ & $28,00 \mathrm{c}$ & $65,75 \mathrm{c}$ & $81,50 \mathrm{~b}$ & $87,75 b$ \\
\hline Aveia-preta & $8,00 \mathrm{~d}$ & $10,50 \mathrm{~d}$ & $44,50 \mathrm{e}$ & $54,50 \mathrm{~d}$ & $60,75 \mathrm{c}$ \\
\hline Guandu-anão + milheto & $6,25 \mathrm{~d}$ & $20,25 \mathrm{~d}$ & $57,00 \mathrm{~d}$ & $67,75 \mathrm{c}$ & $77,25 b$ \\
\hline Guandu-anão & $6,25 \mathrm{~d}$ & $15,25 \mathrm{~d}$ & $42,25 \mathrm{e}$ & $56,50 \mathrm{~d}$ & $61,25 \mathrm{c}$ \\
\hline Milheto & $4,25 \mathrm{~d}$ & $14,75 \mathrm{~d}$ & $27,50 \mathrm{f}$ & $33,75 \mathrm{e}$ & $38,50 \mathrm{~d}$ \\
\hline Testemunha & $3,75 \mathrm{c}$ & $17,25 \mathrm{~d}$ & $51,25 \mathrm{~d}$ & $75,25 \mathrm{~b}$ & $79,00 \mathrm{~b}$ \\
\hline
\end{tabular}

${ }^{(1)}$ Valores médios das avaliações realizadas em 2009 e 2010. ${ }^{(2)}$ Médias seguidas de letras iguais, nas colunas, pertencem a um mesmo grupo, pelo teste de Scott-Knott, a $5 \%$ de probabilidade. 
em comparação à altura média do feijão-de-porco, que foi de $0,53 \mathrm{~m}$; já o sorgo, apresentou altura de $1,15 \mathrm{~m}$. A semelhança entre a taxa de cobertura dos dois consórcios pode ser explicada pela própria morfologia da leguminosa, principalmente suas folhas largas, que cobrem rapidamente toda a área em sua volta, independentemente da planta companheira. Pelo mesmo motivo, o consórcio feijão-de-porco + milheto apresentou crescimento inicial um pouco mais lento; porém, na época do corte, apresentou a mesma cobertura dos dois outros consórcios. A capacidade do feijão-de-porco em cobrir rapidamente o solo também foi observada por Favero et al. (2001), que encontraram taxa de cobertura de $83 \%$ aos 56 DAE. A taxa de cobertura do consórcio do feijão-de-porco com as três poáceas foi superior à da testemunha.
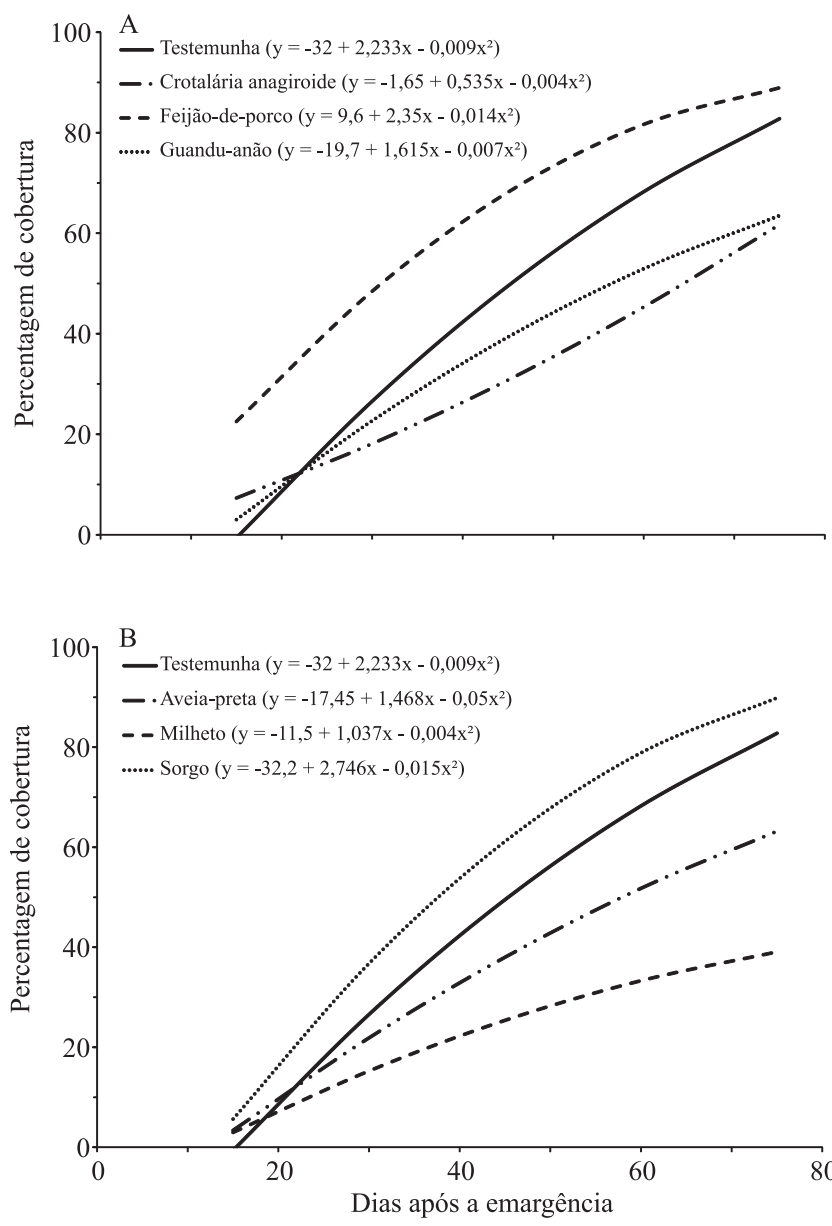

Figura 2. Cobertura do solo proporcionada pelo cultivo solteiro de: A, leguminosas; e B, poáceas. Os resultados referem-se às médias entre as avaliações realizadas em 2009 e 2010 .
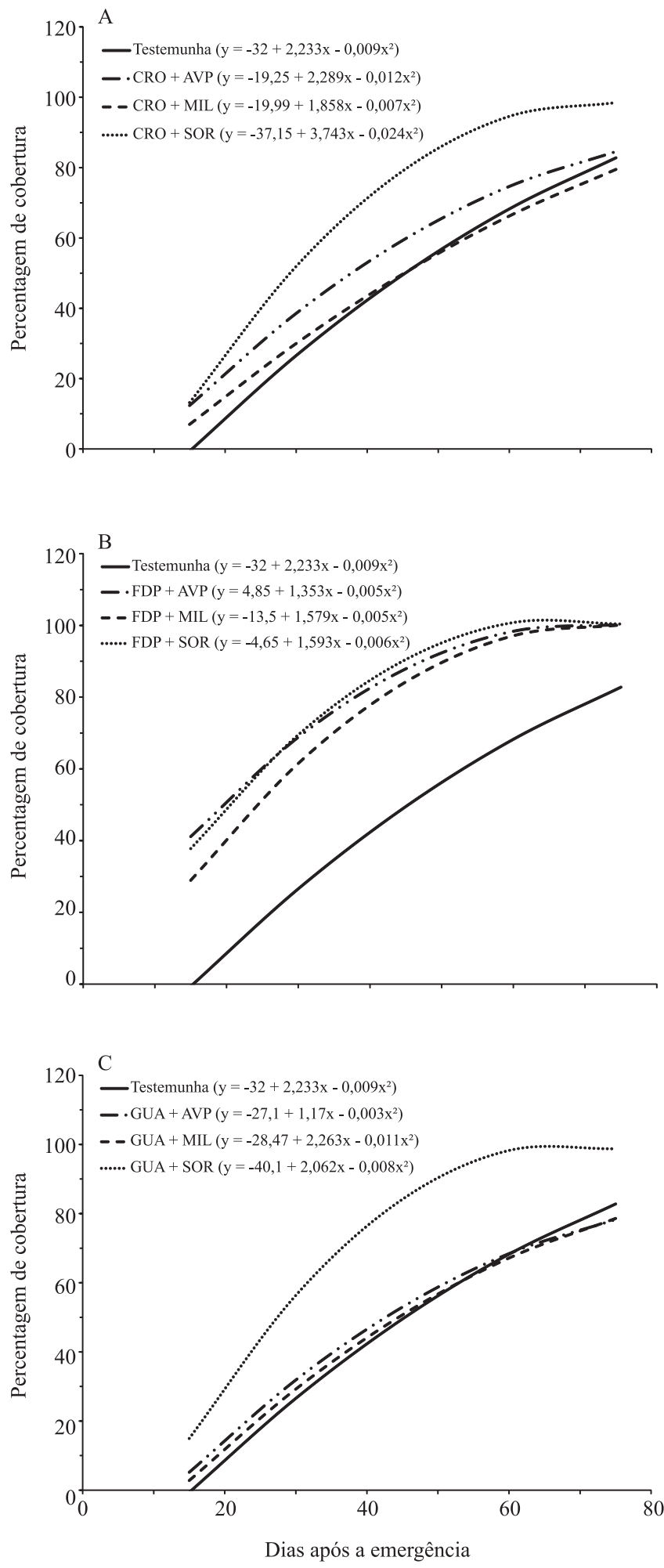

Figura 3. Cobertura do solo proporcionada pelo consórcio das poáceas aveia-preta (AVP), milheto (MIL) e sorgo (SOR) com: A, crotalária (CRO); B, feijão-de-porco (FDP); e C, guandu-anão (GUA). Os resultados referem-se às médias entre as avaliações realizadas em 2009 e 2010. 
Para o guandu-anão, os consórcios com aveia-preta e milheto apresentaram incremento na taxa de cobertura semelhante ao da vegetação espontânea (testemunha), ao longo do período de avaliação. $\mathrm{O}$ consórcio com sorgo, no entanto, destacou-se, com maior taxa de cobertura do solo (Figura 3).

Em termos gerais, as plantas de cobertura apresentaram baixa produção, tanto de massa de matéria verde como de matéria seca (Tabela 2). Um dos fatores que contribuíram para esse baixo rendimento foi a ausência de adubação, em uma área que, há três anos, não recebia qualquer tipo de fertilizante. De acordo com Spehar \& Lara Cabezas (2000), a avaliação sem a influência de fertilizantes contribui para selecionar as melhores espécies para cultivo no Cerrado, que devem apresentar, entre outras, a característica de rusticidade, com alta eficiência no uso e na ciclagem de nutrientes já existentes no solo, especialmente nitrogênio, fósforo e potássio, uma vez que não se recomenda a fertilização para esse tipo de cultura. Outro fator que concorreu para a baixa produção de biomassa foi a semeadura em período não favorável para o desenvolvimento das plantas.

O sorgo foi a planta de cobertura que produziu maior quantidade de matéria verde, tanto em cultivo solteiro, como em consorciado (Tabela 2). Quando em consórcio com guandu-anão e feijão-de-porco, sua produção de matéria verde foi maior que quando em consórcio com crotalária anagiroide. Esses dados comprovam a rusticidade e a resistência ao déficit hídrico dessa espécie, que recebeu, durante seu ciclo vegetativo, $228 \mathrm{~mm}$ de chuva, em 2009, e apenas $103 \mathrm{~mm}$, em 2010. Para sorgo semeado em setembro, na mesma área e sob as mesmas condições de fertilização, Barros (2009) obteve produção de $30,8 \mathrm{Mg} \mathrm{ha}^{-1}$ de matéria verde. O guandu-anão foi a espécie que produziu a menor quantidade de matéria verde, tendo-se equiparado à testemunha com vegetação espontânea. Também verificou-se baixa produção no tratamento com crotalária anagiroide. A baixa produção de matéria verde dessas leguminosas pode ser atribuída à redução da quantidade de horas-luz, que começa a se acentuar em maio. A sensibilidade das leguminosas ao fotoperíodo, mencionada por Carvalho \& Amabile (2006), é menos acentuada no feijão-de-porco, de acordo com o presente trabalho.

A correlação entre a produção de matéria verde e de matéria seca após o corte foi, naturalmente, bastante elevada, para todos os tratamentos $(\mathrm{r}=0,99 * *)$. O tratamento feijão-de-porco + sorgo

Tabela 2. Massa de matéria verde (MV) e seca (MS) de plantas de cobertura após o corte, relação MV/MS (RVS), percentagem de matéria seca de poáceas nos tratamentos consorciados, percentagem de cobertura de palhadas de plantas de cobertura em setembro e outubro, e massa de matéria seca de palhada de plantas de cobertura antes da semeadura da cultura sucessora ${ }^{(1)}$.

\begin{tabular}{|c|c|c|c|c|c|c|c|}
\hline \multirow[t]{3}{*}{ Espécie } & \multirow[t]{2}{*}{ Matéria verde } & \multirow[t]{2}{*}{ Matéria seca } & \multirow[t]{3}{*}{ RVS } & \multirow{2}{*}{$\begin{array}{l}\text { Matéria seca } \\
\text { de poáceas }\end{array}$} & \multicolumn{2}{|c|}{ Cobertura de palhadas } & \multirow{3}{*}{$\begin{array}{c}\text { Matéria seca } \\
\text { de palhada } \\
\left(\mathrm{kg} \mathrm{ha}^{-1}\right)\end{array}$} \\
\hline & & & & & Setembro & Outubro & \\
\hline & \multicolumn{2}{|c|}{-------------(kg ha-1)------------- } & & ---------- & $--(\%)--$ & --- & \\
\hline Guandu-anão + sorgo & $15.204 \mathrm{a}$ & $4.657 \mathrm{a}$ & $3,32 b$ & 87,45 & $76,25 b$ & $42,50 \mathrm{~b}$ & $2.254 \mathrm{c}$ \\
\hline Feijão-de-porco + sorgo & $15.155 \mathrm{a}$ & 4.611a & $3,30 \mathrm{~b}$ & 58,94 & $90,00 \mathrm{a}$ & $72,50 \mathrm{a}$ & $3.128 \mathrm{a}$ \\
\hline Sorgo & $14.465 \mathrm{a}$ & $4.756 \mathrm{a}$ & $3,10 \mathrm{~b}$ & - & $72,50 \mathrm{~b}$ & $45,00 \mathrm{~b}$ & $2.692 b$ \\
\hline Crotalária anagiroide + sorgo & $12.378 b$ & $4.129 b$ & $3,02 b$ & 77,49 & $76,25 b$ & $46,25 b$ & $2.086 \mathrm{~d}$ \\
\hline Feijão-de-porco + milheto & $8.260 \mathrm{c}$ & $2.494 \mathrm{c}$ & $3,35 b$ & 46,11 & $46,25 d$ & $16,25 d$ & $960 f$ \\
\hline Feijão-de-porco & $8.116 \mathrm{c}$ & $2.369 \mathrm{c}$ & $3,40 \mathrm{~b}$ & - & $61,25 \mathrm{c}$ & $26,25 \mathrm{c}$ & $1.382 \mathrm{e}$ \\
\hline Feijão-de-porco+ aveia-preta & $8.114 c$ & $2.486 \mathrm{c}$ & $3,30 \mathrm{~b}$ & 24,17 & $37,50 \mathrm{e}$ & $11,25 \mathrm{e}$ & $760 f$ \\
\hline Crotalária anagiroide + milheto & $4.995 d$ & $1.390 \mathrm{~d}$ & $3,50 \mathrm{~b}$ & 79,83 & $33,25 \mathrm{e}$ & $3,50 \mathrm{f}$ & $853 f$ \\
\hline Guandu-anão + milheto & $4.531 \mathrm{~d}$ & $1.390 \mathrm{~d}$ & $3,27 b$ & 73,03 & $29,50 \mathrm{e}$ & $4,00 \mathrm{f}$ & $872 f$ \\
\hline Aveia-preta & $4.216 \mathrm{e}$ & $1.532 \mathrm{~d}$ & $2,75 \mathrm{c}$ & - & $9,00 \mathrm{f}$ & $2,00 f$ & $498 \mathrm{~g}$ \\
\hline Crotalária anagiroide + aveia-preta & $3.706 \mathrm{e}$ & $1.330 \mathrm{~d}$ & $2,80 \mathrm{c}$ & 59,41 & $14,50 \mathrm{f}$ & $2,50 \mathrm{f}$ & $308 \mathrm{~h}$ \\
\hline Milheto & $3.371 \mathrm{f}$ & $968 \mathrm{e}$ & $3,50 \mathrm{~b}$ & - & $15,00 \mathrm{f}$ & $2,75 f$ & $609 \mathrm{~g}$ \\
\hline Guandu-anão + aveia-preta & $3.142 \mathrm{f}$ & $1.214 \mathrm{~d}$ & $2,60 \mathrm{c}$ & 56,85 & $13,00 \mathrm{f}$ & $2,50 \mathrm{f}$ & $548 \mathrm{~g}$ \\
\hline Crotalária anagiroide & $2.676 \mathrm{f}$ & $527 \mathrm{f}$ & $5,27 \mathrm{a}$ & - & $45,00 \mathrm{~d}$ & $9,25 \mathrm{e}$ & $450 \mathrm{~g}$ \\
\hline Guandu-anão & $2.123 \mathrm{~g}$ & $955 \mathrm{e}$ & $2,32 \mathrm{c}$ & - & $17,50 f$ & $3,25 \mathrm{f}$ & $397 \mathrm{~g}$ \\
\hline Testemunha & $1.678 \mathrm{~g}$ & $616 f$ & $2,67 \mathrm{c}$ & - & $27,00 \mathrm{e}$ & $2,25 \mathrm{f}$ & $130 \mathrm{i}$ \\
\hline $\mathrm{CV}(\%)$ & 8,00 & 9,65 & 8,84 & - & 13,72 & 21,32 & 8,99 \\
\hline
\end{tabular}

${ }^{(1)}$ Médias seguidas de letras iguais, nas colunas, pertencem a um mesmo grupo, pelo teste de Scott-Knott, a 5\% de probabilidade. Valores médios das avaliações realizadas em 2009 e 2010. 
produziu a maior quantidade de matéria seca, e, nesse consórcio, o sorgo contribuiu com 58,94\% da matéria seca total. A produção de matéria seca de sorgo, semeado em setembro, encontrada por Barros (2009), em experimento na mesma área e sob as mesmas condições de adubação, foi de $6,95 \mathrm{Mg} \mathrm{ha}^{-1}$. A crotalária anagiroide produziu a menor quantidade de matéria seca, tendo-se igualado à testemunha de vegetação espontânea, seguida do guandu-anão e do milheto (Tabela 2). Teixeira et al. (2010) em área com histórico de quatro anos com cultura do feijoeiro, obtiveram rendimento de $2,36 \mathrm{Mg} \mathrm{ha}^{-1}$ de matéria seca de milheto, semeado no final do período das águas.

A falta de fertilização aliada ao estresse hídrico relacionado à época de plantio são, provavelmente, os principais responsáveis pelo fato de nenhum tratamento ter atingido a média de produção de matéria seca de $5,0 \mathrm{Mg} \mathrm{ha}^{-1}$, considerada como a quantidade adequada de resíduos para se obter boa taxa de cobertura do solo (Menezes et al., 2009). O efeito do déficit hídrico na redução da produção de palhada fica evidente no trabalho de Torres et al. (2008), em que foram obtidos, para sorgo, 7,1 e 4,0 $\mathrm{Mg} \mathrm{ha}^{-1}$ de matéria seca nos períodos das águas e da seca, respectivamente, e, para milheto, 10,3 e 3,6 $\mathrm{Mg} \mathrm{ha}^{-1}$ de matéria seca .

Os valores obtidos a partir da relação massa de matéria verde/massa de matéria seca (RVS) permitiram, de forma preliminar, a classificação das plantas de cobertura quanto ao seu conteúdo de matéria seca, em baixa (RVS $>5$ ), média (RVS de 3 a 5) e alta $($ RVS $<3)$. De acordo com essa classificação, a crotalária anagiroide é a espécie que produz a fitomassa com menor conteúdo de matéria seca, e o guandu-anão e a aveia-preta, as que apresentaram maior conteúdo de matéria seca, seguidas da vegetação espontânea e dos consórcios aveia-preta + crotalária anagiroide e aveia-preta + guandu-anão.

A avaliação das palhadas de cobertura no início de setembro, após o período da seca, indicou que houve pouca perda de massa de matéria seca durante esse período (Tabelas 1 e 2), provavelmente em decorrência da baixa precipitação (Figura 1). Altas taxas de decomposição da fitomassa de resíduos vegetais são observadas em condições de elevada temperatura e precipitação que ocorrem no período das águas (Boer et al., 2008; Leite et al., 2010). Soratto et al. (2012) verificaram redução de $50 \%$ na matéria seca de milheto após 33 dias no campo, no período das águas.
A correlação entre percentagem de cobertura e produção de matéria seca foi altamente significativa $(\mathrm{r}=0,87 * *)$, e os tratamentos que produziram maior quantidade de palha - todos contendo sorgo - proporcionaram maior cobertura no início de setembro. A crotalária anagiroide, no entanto, propiciou maior cobertura do solo em setembro que o guandu-anão, embora tenha produzido menos palha. Pode-se atribuir essa diferença, em relação ao comportamento geral, ao fato de, na época da avaliação, terem decorrido, em média, 50 dias do corte da crotalária anagiroide e 90 dias do corte do guandu-anão.

A percentagem de cobertura obtida no final de outubro teve correlação altamente significativa com a observada no início de setembro $\left(\mathrm{r}=0,94^{* *}\right)$ e, também, com a massa de matéria seca avaliada logo após o corte das plantas de cobertura $(\mathrm{r}=0,92 * *)$. Apesar de decorridos 60 dias (do início de setembro ao final de outubro) entre uma avaliação e outra, com a ocorrência de quantidade razoável de precipitação (Figura 1), o comportamento da cobertura fosse semelhante. As parcelas com sorgo proporcionaram a maior percentagem de cobertura, com destaque para o consórcio feijão-de-porco + sorgo, que apresentou redução de apenas 19,44\% no período. Entre as leguminosas com baixa produção de palha, a crotalária anagiroide propiciou maior cobertura que o guandu-anão.

As reduções na percentagem de cobertura do solo pela palhada foram relativamente pequenas nos tratamentos com sorgo $(37,93 \%)$ e nos consórcios desta poácea com crotalária anagiroide $(39,34 \%)$ e guandu-anão $(44,26 \%)$ (Tabela 2). O tratamento-controle, com plantas infestantes, apresentou maior redução na cobertura do solo $(91,67 \%)$, e, entre as plantas de cobertura estudadas, a maior redução foi observada para o consórcio crotalária anagiroide + milheto (89,47\%). Sodré Filho et al. (2004) avaliaram a percentagem de cobertura de plantas de cobertura em agosto e outubro, no Distrito Federal, e encontraram redução, nessa variável, de $60,49 \%$ para aveia-preta; $42,53 \%$ para crotalária anagiroide; $63,75 \%$ para guandu-anão; e 62,65\% para milheto. Essa redução foi menor que a obtida no presente trabalho, que foi de $77,77 \%$ para aveia-preta; $79,44 \%$ para crotalária anagiroide; 81,42\% para guandu-anão; e 81,66\% para milheto, provavelmente pela menor precipitação ocorrida durante o período de avaliação $(80 \mathrm{~mm})$, no trabalho desses autores. 
A avaliação da palhada das plantas de cobertura realizada antes da semeadura da cultura sucessora, em outubro (Tabela 2), também apresentou correlação altamente significativa com a produção de matéria seca avaliada logo após o corte das plantas $\left(\mathrm{r}=0,95^{* *}\right)$. Consequentemente, os tratamentos que produziram maior quantidade de matéria seca, todos contendo sorgo, apresentaram maiores massas de matéria seca de palhada nessa segunda pesagem. Deve-se levar em consideração que os tratamentos com sorgo foram cortados, em média, 15 dias após os tratamentos com milheto e aveia-preta, tendo permanecido menos tempo em contato com o solo. A testemunha, com vegetação espontânea, e o consórcio crotalária anagiroide + aveia-preta foram os tratamentos que apresentaram menor massa de palhada antes da semeadura da cultura sucessora.

\section{Conclusões}

1. Entre as leguminosas avaliadas, o feijão-de-porco apresenta a maior taxa de cobertura do solo até a época de corte, em comparação ao guandu-anão e à crotalária anagiroide; já entre as poáceas, o sorgo apresenta a maior taxa de cobertura do solo até a época de corte, quando comparado à aveia-preta e ao milheto.

2. O milheto, em cultivo solteiro, proporciona a menor taxa de cobertura do solo até a época de corte.

3. Das espécies avaliadas, sorgo, sorgo + feijãode-porco e sorgo + guandu-anão apresentam a maior produção de matéria verde e seca, enquanto $\mathrm{o}$ guandu-anão apresenta a menor produção de matéria verde e a crotalária, a menor produção de matéria seca.

4. Na época da implantação da cultura sucessora, a maior quantidade de palha cobrindo o solo é proveniente do consórcio feijão-de-porco + sorgo.

\section{Referências}

BALBINOT JÚNIOR, A.A.; MORAES, A.; PELISSARI, A.; DIECKOW, J.; VEIGA, M. Formas de uso do solo no inverno e sua relação com a infestação de plantas daninhas em milho (Zea mays) cultivado em sucessão. Planta Daninha, v.26, p.569-576, 2008. DOI: $10.1590 / \mathrm{S} 0100-83582008000300012$.

BALBINOT JÚNIOR, A.A.; CARVALHO, P.C.F.; VEIGA, M.; MORAES, A.; PELISSARI, A. Desempenho da cultura do feijão após diferentes formas de uso do solo no inverno. Ciência Rural, v.39, p.2340, 2009. DOI: 10.1590/S0103-84782009000800011.
BARROS, D.L. Plantas de cobertura e seus efeitos no solo e na cultura do milho verde. 2009. 50p. Dissertação (Mestrado) Universidade Federal de Lavras, Lavras.

BOER, C.A.; ASSIS, R.L.; SILVA, G.P.; BRAZ, A.J.B.P.; BARROSO, A.L.L.; CARGNELUTTI FILHO, A.; PIRES, F.R. Biomassa, decomposição e cobertura do solo ocasionada por resíduos culturais de três espécies vegetais na região Centro-Oeste do Brasil. Revista Brasileira de Ciência do Solo, v.32, p.843-851, 2008. DOI: 10.1590/S0100-06832008000200038.

CARVALHO, A.M. de; AMABILE, R.F. Plantas condicionadoras de solo: interações edafoclimáticas, uso e manejo. In: CARVALHO, A.M. de; AMABILE, R.F. (Ed.). Cerrado: adubação verde. Planaltina: Embrapa Cerrados, 2006. 369p.

CHERR, C.M.; SCHOLBERG, J.M.S.; MCSORLEY, R. Green manure approaches to crop production: a synthesis. Agronomy Journal, v.98, p.302-319, 2006. DOI: 10.2134/agronj2005.0035.

FAVERO, C.; JUCKSCH, I.; ALVARENGA, R.C.; COSTA, L.M. da. Modificações na população de plantas espontâneas na presença de adubos verdes. Pesquisa Agropecuária Brasileira, v.36, p.1355-1362, 2001. DOI: 10.1590/S0100-204X2001001100005.

GIACOMINI, S.J.; AITA, C.; VENDRUSCOLO, E.R.O.; CUBILLA, M.; NICOLOSO, R.S.; FRIES, M.R. Matéria seca, relação $\mathrm{C} / \mathrm{N}$ e acúmulo de nitrogênio, fósforo e potássio em misturas de plantas de cobertura de solo. Revista Brasileira de Ciência do Solo, v.27, p.325-334, 2003. DOI: 10.1590/S010006832003000200012.

LEITE, L.F.C.; FREITAS, R.C.A.; SAGRILO, S.; GALVÃO, S.R.S. Decomposição e liberação de nutrientes de resíduos vegetais depositados sobre Latossolo Amarelo no cerrado Maranhense. Revista Ciência Agronômica, v.41, p.29-35, 2010.

MATHEIS, H.A.S.M.; AZEVEDO, F.A. de; VICTÓRIA FILHO, R. Adubação verde no manejo de plantas daninhas na cultura de citros. Laranja, v.27, p.101-110, 2006.

MESCHEDE, D.K.; FERREIRA, A.B.; RIBEIRO JÚNIOR, C.C. Avaliação de diferentes coberturas na supressão de plantas daninhas no Cerrado. Planta Daninha, v.25, p.465-471, 2007. DOI: $10.1590 / \mathrm{S} 0100-83582007000300005$.

MENEZES, L.A.S.; LEANDRO, W.M.; OLIVEIRA JUNIOR, J.P.; FERREIRA, A.C.B.; SANTANA, J.G.; BARROS, R.G. Produção de fitomassa de diferentes espécies, isoladas e consorciadas, com potencial de utilização para cobertura do solo. Bioscience Journal, v.25, p.7-12, 2009.

SANTOS, H.G. dos; JACOMINE, P.K.T.; ANJOS, L.H.C. dos; OLIVEIRA, V.A. de; OLIVEIRA, J.B. de; COELHO, M.R.; LUMBRERAS, J.F.; CUNHA, T.J.F. (Ed.). Sistema brasileiro de classificação de solos. 2.ed. Rio de janeiro: Embrapa Solos, 2006. $306 \mathrm{p}$.

SILVA, J.A.N.; SOUZA, C.M.A.; SILVA, C.J.; BOTTEGA, S.P. Crescimento e produção de espécies forrageiras consorciadas com pinhão-manso. Pesquisa Agropecuária Brasileira, v.47, p.769-775, 2012. DOI: 10.1590/S0100-204X2012000600006.

SODRÉ FILHO, J.; CARDOSO, A.N.; CARMONA, R.; CARVALHO, A.M. de. Fitomassa e cobertura do solo de 
culturas de sucessão ao milho na Região do Cerrado. Pesquisa Agropecuária Brasileira, v.39, p.327-334, 2004. DOI: 10.1590/ S0100-204X2004000400005.

SORATTO, R.P.; CRUSCIOL, C.A.C.; COSTA, C.H.M.; NETO, J.F.; CASTRO, G.S.A. Produção, decomposição e ciclagem de nutrientes em resíduos de crotalária e milheto, cultivados solteiros e consorciados. Pesquisa Agropecuária Brasileira, v.47, p.1462-1470, 2012. DOI: 10.1590/S0100-204X2012001000008.

SPEHAR, C.R.; LARA CABEZAS, W.A.R. Introdução e seleção de espécies para a diversificação do sistema produtivo nos cerrados. In: ENCONTRO REGIONAL DE PLANTIO DIRETO NO CERRADO, 4., 1999, Uberlândia. Plantio direto na integração lavoura-pecuária: anais. Uberlândia: Universidade Federal de Uberlândia, 2000. p.179-188.
TEIXEIRA, C.M.; CARVALHO, G.J.; ANDRADE, M.J.B.; SILVA, C.A.; PEREIRA, J.M. Decomposição e liberação de nutrientes das palhadas de milheto e milheto + crotalária no plantio direto do feijoeiro. Acta Scientiarum. Agronomy, v.31, p.647-653, 2009. DOI: 10.4025/actasciagron.v31i4.1356.

TEIXEIRA, C.M.; CARVALHO, G.J.; SILVA, C.A.; ANDRADE, M.J.B.; PEREIRA, J.M. Liberação de macronutrientes das palhadas de milheto solteiro e consorciado com feijão-de-porco sob cultivo de feijão. Revista Brasileira de Ciência do Solo, v.34, p.497-505, 2010. DOI: 10.1590/S0100-06832010000200023.

TORRES, J.L.R.; PEREIRA, M.G.; FABIAN, A.J. Produção de fitomassa por plantas de cobertura e mineralização de seus resíduos em plantio direto. Pesquisa Agropecuária Brasileira, v.43, p.421-428, 2008. DOI: 10.1590/S0100-204X2008000300018.

Recebido em 22 de abril de 2011 e aprovado em 18 de janeiro de 2013 